\title{
Diagnosing low-/mid-latitude ionospheric currents using platform magnetometers: CryoSat-2 and GRACE-FO
}

Jaeheung Park ${ }^{1,2^{*}}$, Claudia Stolle ${ }^{3,4}$, Yosuke Yamazaki ${ }^{3}$, Jan Rauberg ${ }^{3}$, Ingo Michaelis ${ }^{3}$ and Nils Olsen ${ }^{5}$

\begin{abstract}
Electric currents flowing in the terrestrial ionosphere have conventionally been diagnosed by low-earth-orbit (LEO) satellites equipped with science-grade magnetometers and long booms on magnetically clean satellites. In recent years, there are a variety of endeavors to incorporate platform magnetometers, which are initially designed for navigation purposes, to study ionospheric currents. Because of the suboptimal resolution and significant noise of the platform magnetometers, however, most of the studies were confined to high-latitude auroral regions, where magnetic field deflections from ionospheric currents easily exceed $100 \mathrm{nT}$. This study aims to demonstrate the possibility of diagnosing weak low-/mid-latitude ionospheric currents based on platform magnetometers. We use navigation magnetometer data from two satellites, CryoSat-2 and the Gravity Recovery and Climate Experiment Follow-On (GRACE-FO), both of which have been intensively calibrated based on housekeeping data and a high-precision geomagnetic field model. Analyses based on 8 years of CryoSat-2 data as well as $\sim 1.5$ years of GRACE-FO data reproduce well-known climatology of inter-hemispheric field-aligned currents (IHFACs), as reported by previous satellite missions dedicated to precise magnetic observations. Also, our results show that C-shaped structures appearing in noontime IHFAC distributions conform to the shape of the South Atlantic Anomaly. The F-region dynamo currents are only partially identified in the platform magnetometer data, possibly because the currents are weaker than IHFACs in general and depend significantly on altitude and solar activity. Still, this study evidences noontime F-region dynamo currents at the highest altitude $(717 \mathrm{~km}$ ) ever reported. We expect that further data accumulation from continuously operating missions may reveal the dynamo currents more clearly during the next solar maximum.
\end{abstract}

Keywords: Platform magnetometers, CryoSat-2, GRACE-FO, Inter-hemispheric field-aligned currents, F-region dynamo currents

\section{Introduction}

There exist many different systems of electric currents in the terrestrial ionosphere. Among them, field-aligned currents (FACs) in the auroral ionosphere (e.g., Blagau and Vogt 2019) generate the largest changes in the geomagnetic field, whose magnitude can exceed $100 \mathrm{nT}$ when observed by low-earth-orbit (LEO) satellites. The second strongest magnetic deviations come from the

\footnotetext{
*Correspondence: pj@kasi.re.kr

1 Space Science Division, Korea Astronomy and Space Science Institute, Daejeon, South Korea

Full list of author information is available at the end of the article
}

equatorial electrojet (EEJ) flowing along the dip equator in the ionospheric E-layer (Lühr and Maus 2006; Yamazaki and Maute 2017) and auroral electrojets in the high-latitude E-layer (Smith et al. 2017), both of which can generate deflections of the order of $10 \mathrm{nT}$ at LEO (e.g., Alken et al. 2015, Figure 1).

Also, there are other ionospheric current systems with weaker magnetic effect than the two mentioned above. To name a few, we have solar quiet (Sq) currents flowing in the ionospheric E-layer (Yamazaki and Maute 2017), inter-hemispheric field-aligned currents (IHFACs) connecting the two Sq systems in respective hemispheres (Shinbori et al. 2017; Lühr et al. 2015, 2019), 
gravity-driven horizontal currents (Lühr and Maus 2006; Maute and Richmond 2017), pressure-driven currents which counter-balance plasma density inhomogeneity (Lühr et al. 2003; Stolle et al. 2006; Alken et al. 2016; Maute and Richmond 2017; Rodríguez-Zuluaga et al. 2019; Laundal et al. 2019), wind-driven dynamo currents flowing vertically in the ionospheric F-layer (Lühr and Maus 2006), horizontal currents across the polar cap closing net auroral FACs (Lühr and Zhou 2020, and references therein), and low-/mid-latitude small-scale FACs resulting from a divergence of background currents by ionospheric irregularities (Park et al. 2009; RodríguezZuluaga et al. 2017; Yin et al. 2019). There also exist magneto-hydrodynamic (MHD) waves propagating in the ionosphere and accompanying currents, such as Pc3 (Heilig and Sutcliffe 2016) and Pc1 pulsations (Kim et al. 2018; Gou et al. 2020).

Ground-based magnetic observations have been useful in studying ionospheric currents for centuries. Still, the data cannot constrain all the ionospheric current systems due to ground magnetic field perturbations including ionospheric currents, FACs, ground-induced currents, and magnetospheric currents (Fukushima 1976). In situ measurements are indispensable for proper reconstructions of ionospheric currents. Though electric current is simply the net flux of positively and negatively charged particles, it is hard to estimate electric currents by counting particles onboard artificial satellites, because of difficulties in instrumentation (e.g., Dunlop et al. 2018, p. 68). As a result, ionospheric current systems have conventionally been diagnosed by combining the Ampere's induction law and data from science-grade magnetometers onboard LEO satellites: especially suites equipped with long booms (to avoid spacecraft bus noise), vector field magnetometers (to get full 3-dimensional vectors), and absolute scalar magnetometers (for continuous inflight calibration and corrections for sensor axis distortion). Those systems include, since the seminal mission of Magsat in the 1970s (e.g., Maeda et al. 1982), Ørsted (e.g., Neubert et al. 2001), Satélite de Aplicaciones Científicas-C (SAC-C; Colomb and Varotto 2003), Challenging Minisatellite Payload (CHAMP; Reigber et al. 2005), and the European Space Agency (ESA)'s Swarm constellation (Friis-Christensen et al. 2006). Related studies on ionospheric currents using data from these satellites are, to name a few, Yamashita and Iyemori (2002) for Ørsted, Alken and Maus (2007) for SAC-C, Lühr et al. (2003) for CHAMP, and Lühr et al. (2015) for Swarm constellation. A review of scientific studies from satellite-based highprecision magnetometers is provided in Olsen and Stolle (2012).

In recent years, there have been active endeavors to make use of navigation magnetometers placed on the satellite body ('platform magnetometers' hereafter) for diagnosing ionospheric currents. The most famous one among them is the Active Magnetosphere and Planetary Electrodynamics Response Experiment (AMPERE) project. It is based on the commercial Iridium and IridiumNEXT satellite constellations, which consist of several tens of satellites uniformly distributed around the globe at an altitude of $780 \mathrm{~km}$. Based on their platform magnetometers, the AMPERE project produces global-scale maps of high-latitude field-aligned currents (FACs) every $2 \mathrm{~min}$ (https://ampere.jhuapl.edu/). However, due to the suboptimal noise level of the magnetometer outputs (>70 nT) (Anderson et al. 2000), the project only addresses high-latitude FACs (e.g., McGranaghan et al. 2017), which can generate magnetic field deflections of the order of $100 \mathrm{nT}$ (e.g., Wu et al. 2017) with FAC density beyond $1000 \mathrm{nA} / \mathrm{m}^{2}$. Detailed descriptions on the current density estimation methods of AMPERE are given in Anderson et al. (2002, 2014).

The purpose of this study is to demonstrate the ability of platform magnetometers, e.g., on CryoSat- 2 and Gravity Recovery and Climate Experiment Follow-On (GRACE-FO), after extensive calibration effort during post-processing, to diagnose weaker ionospheric currents flowing at low-/mid-latitude regions, which typically amounts only to a few $\mathrm{nA} / \mathrm{m}^{2}$ at LEO: approximately 100 times weaker than typical high-latitude FAC density. In the following, "Satellites, instruments, and data processing methods" section is dedicated to introducing the satellite missions and to describing their magnetic data as well as the method of a current estimation out of the magnetic field data. "Results" section presents the climatology of low-/mid-latitude ionospheric currents reconstructed by platform magnetometer data. Discussions on the results will be given in "Discussion" section, and we draw conclusions in the last section.

\section{Satellites, instruments, and data processing methods}

CryoSat-2 belongs to ESA's Living Planet Program and aims to observe the Earth's ice in Arctic and Antarctic regions. The satellite was launched into a polar circular orbit (inclination angle $\sim 92^{\circ}$ ) at an altitude of about $717 \mathrm{~km}$ on 08 April 2010. The local time (LT) of the orbit precesses slowly with a speed of $12 \mathrm{~h}$ every 8 months (1.5 $\mathrm{h}$ per month). It carries three flux-gate magnetometers (FGM) and star trackers (Olsen et al. 2020). Based on a geomagnetic field model, CHAOS (https://www.space .dtu.dk/english/research/scientific_data_and_models/ magnetic_field_models), the platform magnetometer data have been calibrated intensively, details of which are given in Olsen et al. (2020). The data rate is $0.25 \mathrm{~Hz}$ : this low data rate is not due to data averaging over $4 \mathrm{~s}$, but 
the actual spot reading frequency. All the post-processed data between 2010 and 2018 are open to the public at the ESA's web page: https://swarm-diss.eo.esa.int/\#swarm $\% 2 \mathrm{~F} \% 23 \mathrm{CryoSat}-2$. In this study, we use the combined and filtered data out of all the three FGM's (B_NEC as described in Table 3 of Olsen et al. 2020).

GRACE-FO is a follow-on mission of the GRACE twins decommissioned in October 2017, and the chief science goal is a precise measurement of the Earth's gravity field. On 22 May 2018, two GRACE-FO satellites were launched into a polar orbit (inclination angle $\sim 89^{\circ}$ ) whose altitude is about $490 \mathrm{~km}$. The LT precession rate is about $2.2 \mathrm{~h}$ per month. The satellites carry flux-gate magnetometers as a part of the attitude-orbit control system. Their magnetic field data have been calibrated at GeoForschungsZentrum (GFZ) (Stolle et al., submitted to Earth Planets and Space). Between the two GRACE-FO satellites (FO1 and FO2), we opt to use only GRACE-FO1 because of the magnetically cleaner data than those of GRACE-FO2. Note that the GRACE-FO altitude is below that of CryoSat- 2 by about $230 \mathrm{~km}$ and that little temporal overlap (only a part of the year 2018) exists between their data sets used here. The cadence of GRACE-FO magnetometer data is $1 \mathrm{~s}$.

Vertical current density is estimated from the magnetic field data according to the Ampere's law: the curl of B-field is proportional to local current density. As singlespacecraft observations are one-dimensional along the track, which makes the Ampere's law an ill-posed problem, we assume that ionospheric currents form infinite planes with negligible temporal variations over two adjacent B-field measurements used for current density estimation ( $4 \mathrm{~s}$ for CryoSat-2 and $1 \mathrm{~s}$ for GRACE-FO). Note that the vertical current density was estimated based on the assumption that the planar current sheet is perpendicular to the orbit plane (Ritter and Lühr 2013). After making corrections for core, lithospheric, and magnetospheric fields using a geomagnetic field model, the vertical current density can be estimated from the along-track difference of the ionospheric magnetic field, which will be used in climatological studies in the following sections. Detailed descriptions of the current density estimation are given in Ritter and Lühr (2013, section 3. Determination of the Single-Satellite Solution).

In the following statistics, we divide 1 year into three Lloyd seasons. Combined equinox consists of March, April, September, and October. June (December) solstice is composed of May, June, July, and August (November, December, January, and February). These definitions follow the conventions adopted by Lühr et al. (2019). Figure 1 presents data coverage as a function of MLT and day-of-year: (a) CryoSat-2, and (b) GRACE-FO. Seasonal boundaries are annotated on the right. Ideally, the two-dimensional spaces in Fig. 1 should be uniformly red so that there would be no aliasing between MLT and seasonal variations. However, actual data coverage can hardly achieve such an ideal level because of spacecraft orbit characteristics and limited operation time interval. The half-precession periods, during which a satellite can observe the whole 24-h MLT range, is 8 months for CryoSat-2 and about 5.5 months for GRACE-FO. Within a season defined above (4 months), GRACE-FO cannot visit all the MLT sectors ( $24 \mathrm{~h}$ ) and misses a part of them while CryoSat- 2 can diagnose just a half $(12 \mathrm{~h}$ in MLT). Despite these limitations, defining a season to be 8-month long is unreasonable, and following the conventions in previous studies makes a direct comparison easier. That is why we define a season as described above.

For data binning, we first apply a low-pass filter (window size $\sim 20 \mathrm{~s}$ ) to the original time series of vertical current density, as recommended by Olsen et al. (2020): 5-point Savitzky-Golay filter for CryoSat-2 and 21-point one for GRACE-FO. Though the CryoSat- 2 data used in this study are already filtered (Olsen et al. 2020), we apply the Savitzky-Golay filter to both CryoSat-2 and GRACEFO for straightforward comparison. The smoothed vertical current density is bin-averaged as a function of magnetic latitude (MLAT; vertical axis) and magnetic local time (MLT; horizontal axis) in Fig. 2. The MLAT and MLT are defined in the quasi-dipole coordinate system (Richmond 1995; Laundal and Richmond 2017). The bin size is $1^{\circ}$ in MLAT and $0.2 \mathrm{~h}$ in MLT. All the data points irrespective of geomagnetic activity are included in the statistics. The current density, of which either the magnitude or adjacent difference exceeds $500 \mathrm{nA} / \mathrm{m}^{2}$, are deemed artifacts and are excluded. Also, a whole daily file is neglected if the adjacent difference of vertical current density ever exceeds $500,000 \mathrm{nA} / \mathrm{m}^{2}$ or a daily average of vertical current density deviates significantly from zero, beyond $\pm 10 \mathrm{nA} / \mathrm{m}^{2}$.

\section{Results \\ IHFACs}

Figure 2 shows vertical current density representing IHFACs (i.e., hemispherically anti-symmetric component). The solar and geomagnetic activity was generally low during the CryoSat- 2 observation periods. The mean and standard deviation of the $\mathrm{F}_{10.7}$ index from 01 January 2011 to 31 December 2018 were $108 \pm 42$ solar flux unit (sfu), and only a few magnetic storms occurred with $K_{\mathrm{p}}$ values above 4 . Red and blue colors correspond to vertically upward (and presumably field-aligned) and downward (and also field-aligned) directions, respectively. In brief, we may construe that IHFACs in Fig. 2 flow from the red area to the blue area between conjugate points (i.e., points with the same $\mid$ MLAT $\mid$ but in the opposite 

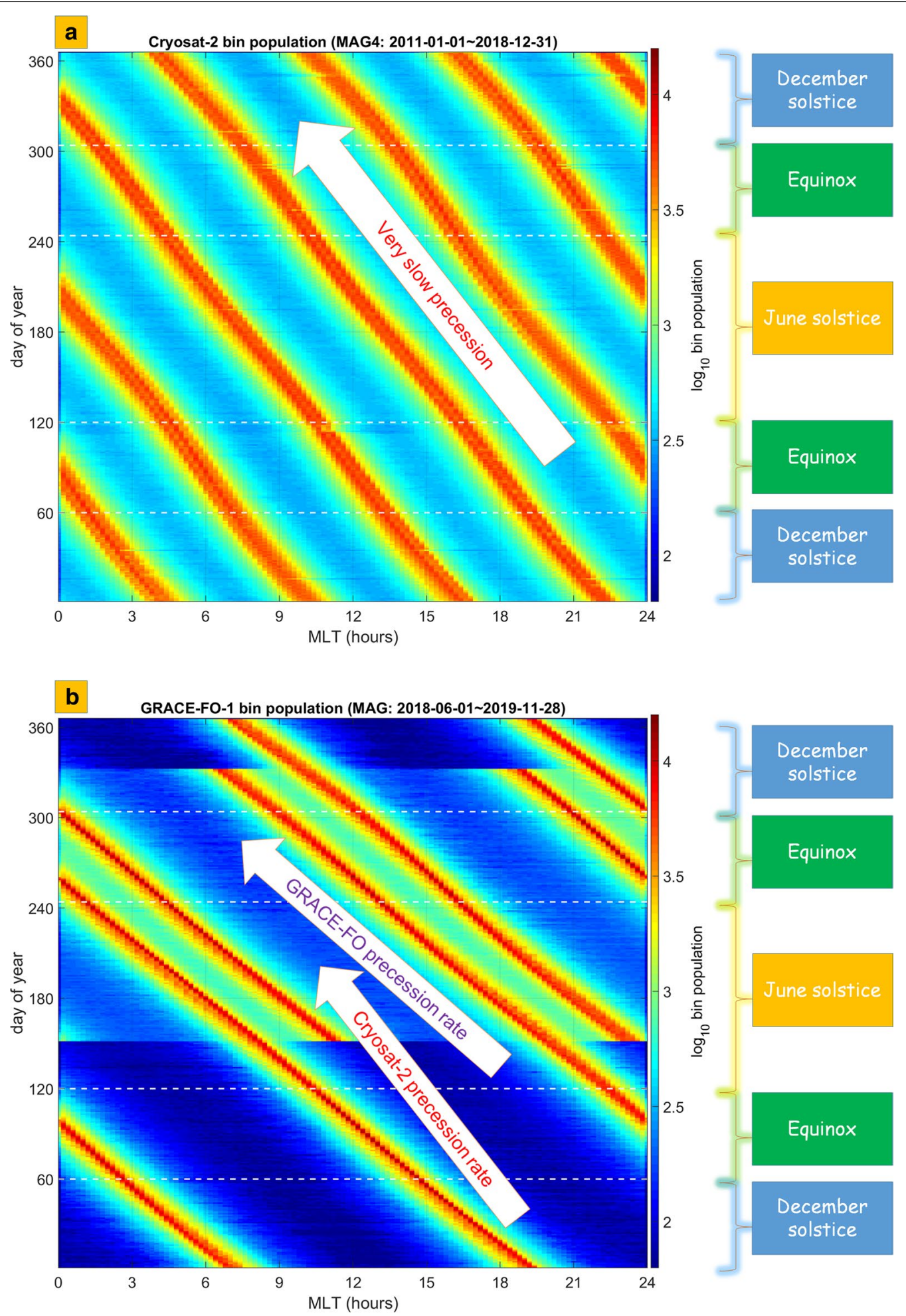

Fig. 1 Data coverage as a function of MLT and day-of-year for $\mathbf{a}$ CryoSat-2 and $\mathbf{b}$ GRACE-FO. Borders for different seasons are given as annotations on the right-hand side. The 'MAG4' in the title of the top panel signifies a combined solution of B-field from the three magnetometers onboard CryoSat-2 


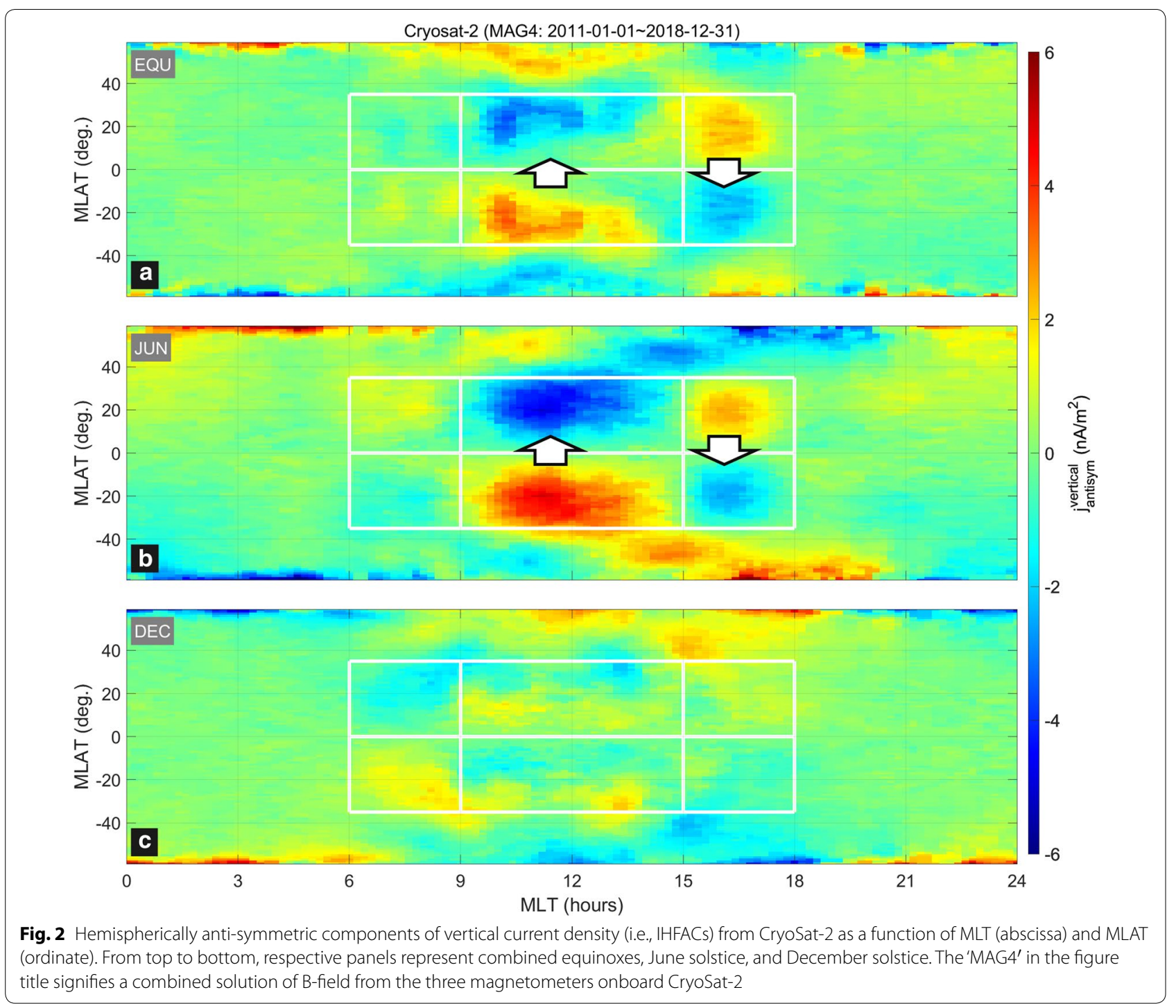

hemispheres). Note that Fig. 2 represents 'vertical' current density in the zenith direction, and that we did not multiply them with an obliquity factor. Such a factor reflects nonzero angles between background magnetic field and zenith (i.e., quantitative relationship between field-aligned and vertical currents) and is conventionally used at high latitudes. However, mapping of vertical currents to the main magnetic field direction is not meaningful for regions with low magnetic inclination around the equator (e.g., Ritter and Lühr 2013). A 3-by-3 two-dimensional median filter has been applied to the bin-averages for visual clarity. White squares represent six regimes defined by three MLT regions (dawn/noon/ dusk) and two MLAT ranges (low-/mid-latitudes) following Park et al. (2020). The squares do not delineate strict geophysical borders, but are shown just to guide readers' eyes and to facilitate discussions.
Each panel in Fig. 2 corresponds to a season: (top) combined equinox, (middle) June solstice, and (bottom) December solstice. Following a convention in previous studies (e.g., Yamashita and Iyemori 2002; Park et al. 2011, 2020), we decompose the bin-averaged vertical current density in the MLAT-MLT space into the following two categories. Hemispherically anti-symmetric components (e.g., upward in the northern hemisphere and downward in the south at the conjugate locations) represent IHFACs while symmetric parts (e.g., upward in both hemispheres at the conjugate locations; mirror images across the dip equator) correspond to F-region dynamo currents. The former and the latter will be presented and discussed separately below.

First, we describe current distributions at low latitudes $\left(\mid\right.$ MLAT $\left.\mid<35^{\circ}\right)$ in Fig. 2. Near noon the low-latitude currents during combined equinoxes (Fig. 2a) and June 
solstice (Fig. 2b) are from the Southern Hemisphere (SH) to the Northern Hemisphere $(\mathrm{NH})$ while the direction is reversed around dusk. On the morningside (06-09 MLT), (1) currents during June solstice, albeit weak, have the same polarity as that of dusk, and (2) equinoctial currents have the opposite polarity. In December solstice (bottom panel), the low-latitude currents are weak and exhibit intricate patterns, but we can see well-organized SH-to$\mathrm{NH}$ currents in the morning (06-09 MLT). For all the three seasons nightside (21 MLT 06 MLT via midnight), low-latitude currents are weak. Second, we address current distributions at mid-latitudes $\left(|\mathrm{MLAT}|>35^{\circ}\right)$ in Fig. 2. During combined equinoxes and June solstice the current polarity changes across $\pm 35^{\circ}$ MLAT so that there appear distinct current systems equatorward and poleward of the border. In December solstice the most notable features are strong $\mathrm{NH}$-to-SH currents near dusk at $\mid$ MLAT $\mid>35^{\circ}$. All these features conform to previous Swarm observations using science-grade magnetometers, which were reported by Lühr et al. $(2015,2019)$ and Park et al. (2020). Furthermore, the absolute levels of current density, which are several $\mathrm{nA} / \mathrm{m}^{2}$, also agree well with earlier studies such as Lühr et al. (2019).

Note that during the combined equinoxes (Fig. 2a) IHFACs at low-latitudes $\left(\mid\right.$ MLAT $\left.\mid<35^{\circ}\right)$ are much weaker during 12-15 MLT than 9-12 MLT. Similar prenoonpostnoon asymmetry can also be seen during June solstice (Fig. 2b), but it is not as drastic as in Fig. 2a. This apparent equinox-June discrepancy was not seen in recent Swarm observations (e.g., Lühr et al. 2019; Figure 5; Park et al. 2020; Figure 3). We attribute the discrepancy to the uneven data coverage of CryoSat-2 in the MLT-season space (i.e., to the MLT-season aliasing). In Fig. 1a, data coverage for 12-15 MLT during combined equinoxes are significantly biased towards December solstices, which can make the equinoctial IHFACs in this MLT sector more December-like weak currents, as shown in Fig. 2c.

Figure 3 is the same as Fig. 2, but from GRACE-FO data. The solar and geomagnetic activity is low for the GRACE-FO data used here. The $\mathrm{F}_{10.7}$ index from 01 June 2018 to 28 November 2019 was $70 \pm 3 \mathrm{sfu}$, and only one significant storm occurred during the period (in August 2018 with a $K_{p}$ value up to $7+$ for a short term). The basic patterns we identified earlier in Fig. 2 can also be seen in Fig. 3, albeit slightly noisier. Note that white areas represent data gaps, which show that the data coverage is not as complete as that of CryoSat-2 due to the short mission lifetime (less than two years). Still, the consistency between combined equinoxes (panel a) and June solstice (panel b) is reasonably good. Low-latitude current directions during those seasons are northward near noon and southward at dusk, while current polarity changes near $\pm 35^{\circ}$ MLAT, as expected from previous studies. During December solstice, the current patterns are less well organized than during the other seasons, which is also in general agreement with Fig. 2.

\section{F-region dynamo currents}

In Fig. 4 obtained from CryoSat-2 data, we present the 'hemispherically symmetric' component of vertical currents, which is deemed as F-region dynamo currents. It is generally accepted that zonal winds blowing in the thermosphere drive vertical currents around the dip equator (e.g., Rishbeth 1971a, b). Many satellites (e.g., Olsen 1997; Lühr and Maus 2006; Lühr et al. 2015) gave observational evidence for this current system. We focus on near-equatorial regions $\left(|\mathrm{MLAT}|<10^{\circ}\right.$; inside the white squares), for which most of the previous papers reported F-region dynamo currents (e.g., Olsen 1997, Plate 2; Lühr et al. 2015, Figure 4). Note in Fig. 4, the vertical currents near the equator are not aligned with but mostly perpendicular to background magnetic field. As in Fig. 2, white squares are given to guide readers' eyes. The left and right squares, respectively, represent dayside, where downward equatorial currents are expected, and evening, where equatorial currents are known to flow upward (e.g., Lühr and Maus 2006; Figure 1; Lühr et al. 2015; Figure 4).

Overall, the currents are weaker than the anti-symmetric counterpart shown in Fig. 2. The equatorial downward currents (blue color) at 12-15 MLT during combined equinoxes (panel a) and December solstice (panel c), which are annotated by red arrows, may reflect true F-region dynamo currents. However, in the pre-noon sector (08-12 MLT), there appear weak upward currents at the equator (reddish color). This does not conform to previous studies on the F-region dynamo currents (Lühr and Maus 2006; Park et al. 2010; Lühr et al. 2015), all of which reported downward equatorial currents during daytime and upward equatorial currents at dusk. Hence, it is highly probable that the equatorial currents in Fig. 3, although partly exhibiting F-region dynamo current systems, are affected by instrument noise and artificial signals from the satellite body. Comparable levels of disturbance during the day and at night (after 21 MLT) further support this hypothesis because F-region dynamo currents are much weaker during the nighttime than during daytime (Lühr et al. 2015, Figure 4).

Figure 5 is the same as Fig. 4, but represents GRACEFO data. We can still identify equatorial downward currents (blue color) at 12-15 MLT during combined equinoxes (panel a) and December solstice (panel c), which are annotated by red arrows. These are consistent with the CryoSat-2 observations and may reflect the F-region dynamo currents. However, signals in Fig. 5 are even noisier than in Fig. 4, nightside currents 


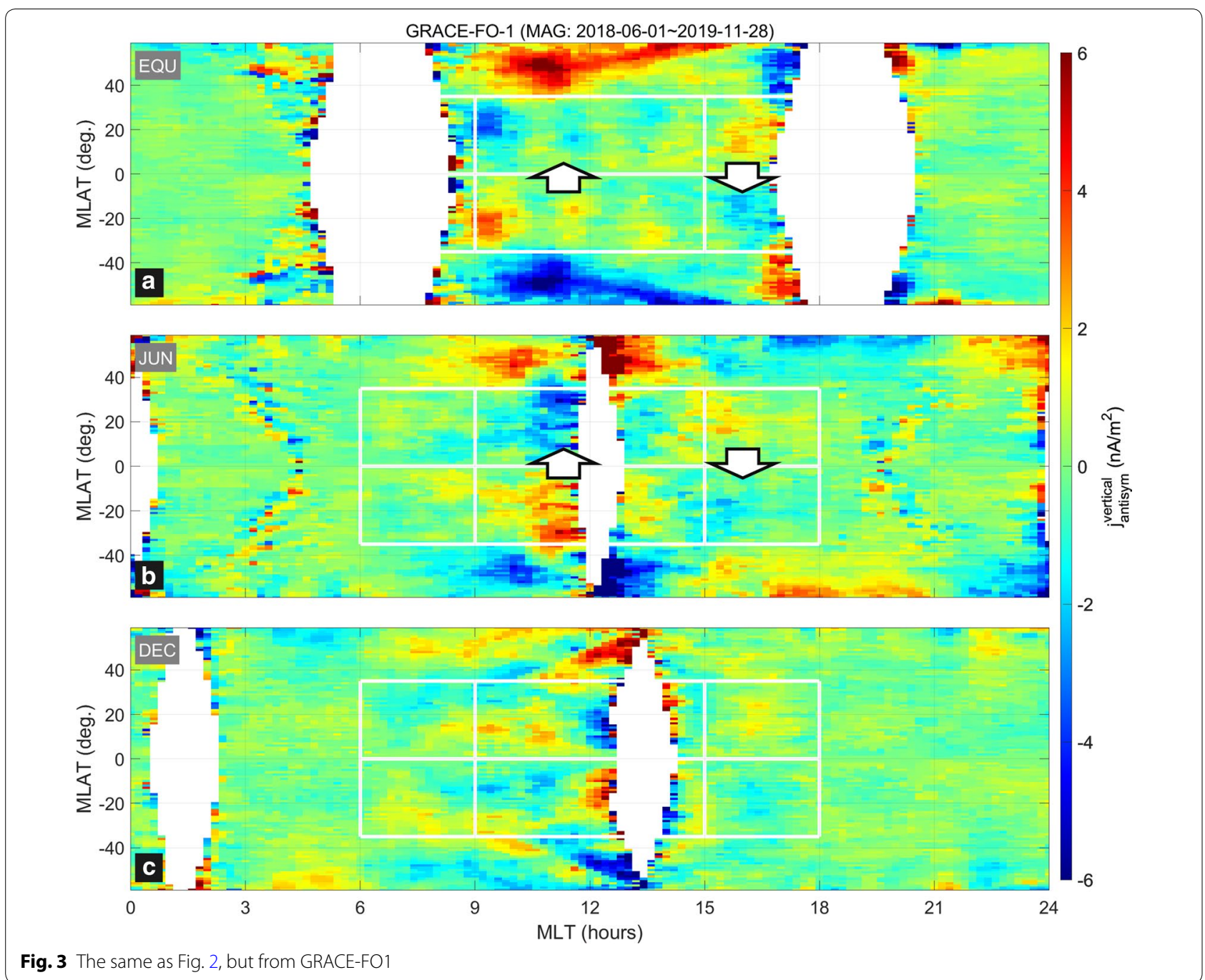

are comparable to dayside ones, and pre-noon currents are still upward contrary to expectations from previous studies for similar altitudes (Lühr et al. 2015, Figure 4). Hence, we construe that the F-region dynamo current signatures may partially exist in the GRACE-FO data, but are significantly affected by noise and/or artefacts.

\section{Discussion}

\section{IHFACs: reproducing science-grade magnetometer} observations

The platform magnetometer data used in this study can reproduce low-/mid-latitude IHFAC climatology reported previously by science-grade magnetometers. Specifically, we have demonstrated in "Results" section that platform magnetometer data of CryoSat-2 and GRACE-FO successfully reproduce IHFAC climatology as reported previously. Statistical distributions of the vertical currents at CryoSat-2 and GRACE-FO altitudes generally agree with previous Swarm and CHAMP studies. The agreement at different altitudes is as expected because IHFACs are, by definition, a field-aligned (then nearly altitude-independent) system from one hemisphere to the other. As an exercise, we have also plotted the IHFACs in the Apex latitude vs. MLT space, where the Apex latitude is defined by a field-aligned mapping of data points down to $110 \mathrm{~km}$ irrespective of the actual observation altitudes (Richmond 1995). The results for CryoSat- 2 and GRACEFO are shown in Figs. 6 and 7, respectively. We can see that Apex latitudes of peak IHFACs at different satellite data (at different altitudes) generally agree with each other, which supports that the detected signals are due to IHFACs (i.e., a current system aligned with the background magnetic field). GRACE-FO results in Fig. 7 exhibit less clear distributions than in Fig. 6, possibly because of the less amount of data (only about 


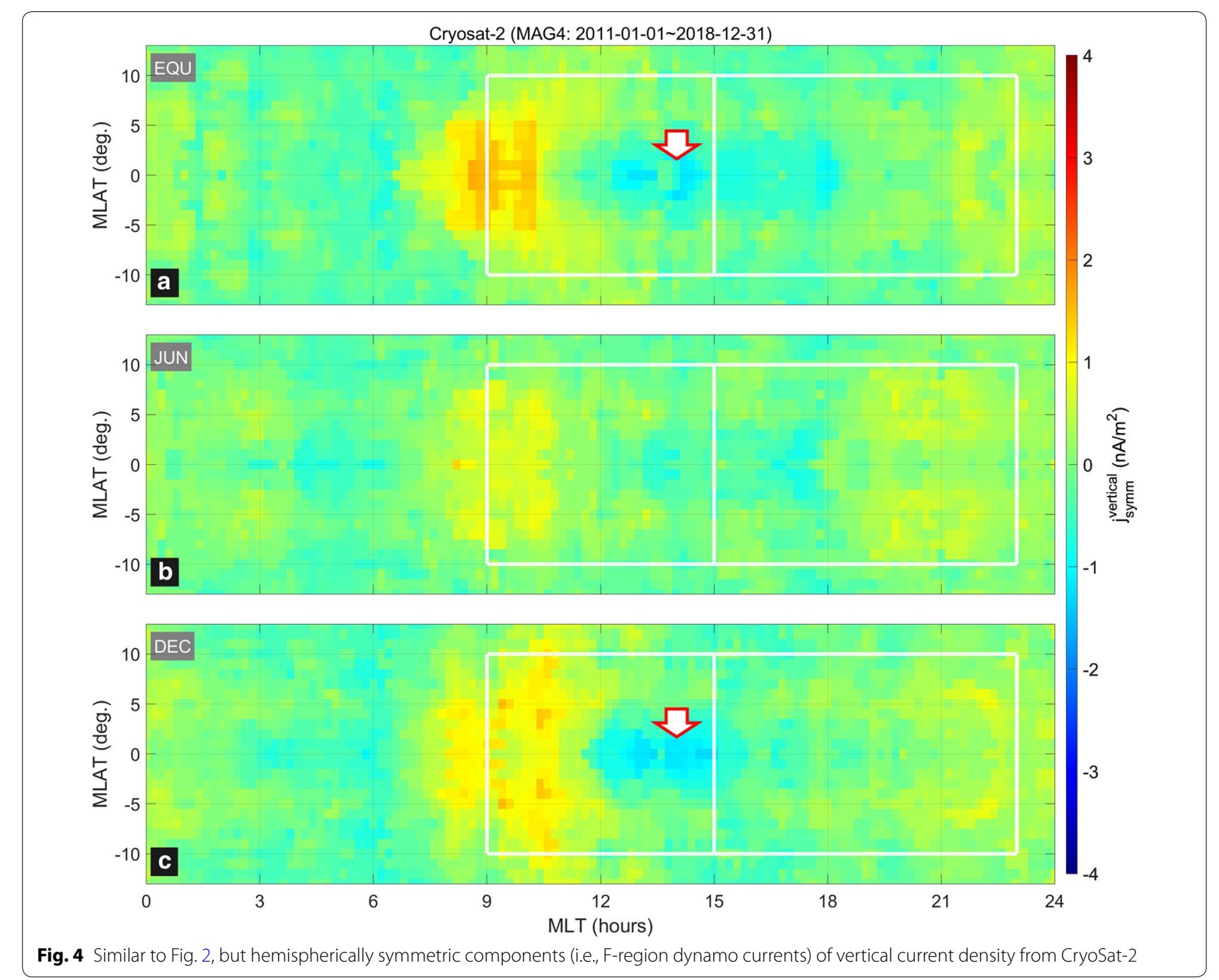

1.5 years) and higher noise level, as we will discuss later in this section.

Encouraged by the promising results from CryoSat-2 (Fig. 2) and its long-term (> 8 years, much longer than the $<2$ years of GRACE-FO) data accumulation, we have further subdivided CryoSat-2 data according to magnetic longitude (MLON) so that the data can be binned in the MLAT-MLT-MLON-season space. The MLON bin size is $5^{\circ}$. Then, we reassemble the vertical current data into separate global maps for three seasons and three MLT sectors: dawn (06-09 MLT), noon (10-14 MLT), and dusk (15-21 MLT). After hemispheric decomposition as described in "Results" section, hemispherically antisymmetric components (i.e., IHFAC) are presented in the nine subpanels in Fig. 8. Note also that a 3-by-3 median filter is applied to all the panels to enhance visual clarity. Each row corresponds to a season: combined equinoxes, June solstice, and December solstice from top to bottom, respectively. Each column from left to right represents an MLT sector: dawn, noon, and dusk in that order.

Overall, Fig. 8 exhibits well-organized patterns, most of which are in reasonably good agreement with previous Swarm observations (Park et al. 2020, Figure 1) despite the different precession rates (i.e., different degrees of season-MLT aliasing) of Swarm and CryoSat-2: see Fig. 1a. As for dependence of IHFACs on longitudes, Park et al. (2020) emphasized a few notable features in the Swarm global maps near local noon, which are relevant to the middle column in our Fig. 8 highlighted by a red rectangle. During combined equinoxes and June solstice, noontime low-latitude IHFACs in Swarm data showed wavenumber -4 or -5 patterns along the zonal direction, which is also manifest in our Fig. 8e and partly for the equinoctial data in Fig. 8d: see the bead-like structures around the equator annotated by vertical arrows. Also, Swarm encountered a 

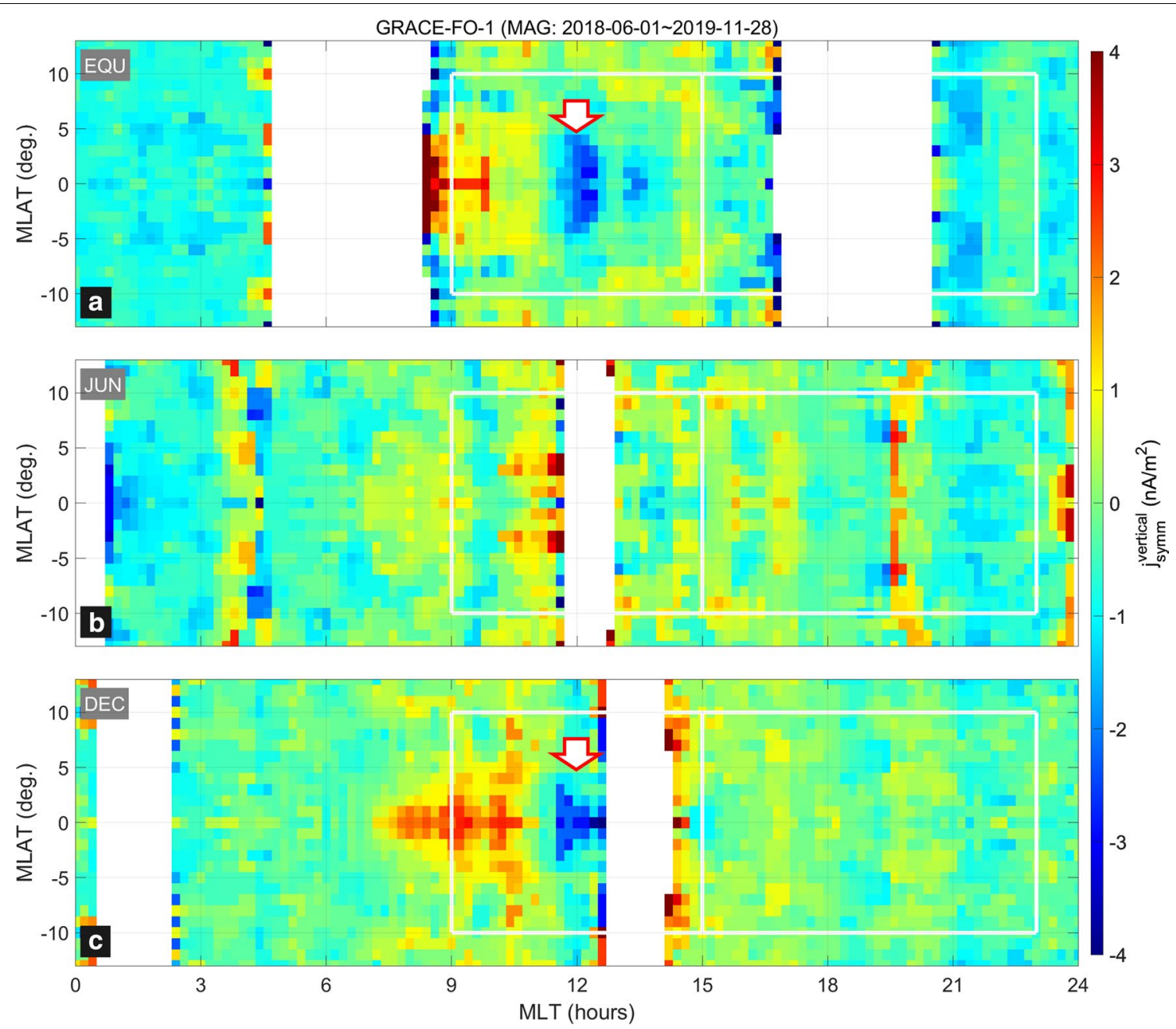

Fig. 5 The same as Fig. 4, but from GRACE-FO1

clear ' $\mathrm{C}$ '-shaped pattern in the noontime maps, which traversed from the North Atlantic to South America during combined equinoxes and June solstice. CryoSat-2 data also exhibit this 'C-shaped' pattern near the white dashed curves in Fig. 8d, e. The C-shape in the $\mathrm{SH}$ is nearly collocated with the South Atlantic Anomaly, which is annotated with solid white curves (magnetic field magnitude of 23,000 nT and 26,000 nT). While some previous studies reported peculiar behavior of IHFACs around the SAA (e.g., Park et al. 2011; Lühr et al. 2019), they basically focused on lowlatitude $\left(|\mathrm{MLAT}|<35^{\circ}\right)$ IHFACs. Our Fig. 8 shows the first evidence that not only low-latitude $\left(|\operatorname{MLAT}|<35^{\circ}\right)$ IHFACs but also mid-latitude ones ( $\mid$ MLAT $\mid>35^{\circ}$ ) reflect the shape of the SAA for noontime during combined equinoxes and June solstice. This $\mathrm{C}$-shape may be partly explained in terms of enhanced conductance in the SAA and concomitant summer-like Sq currents, as discussed extensively in Lühr et al. (2019). For example, low-latitude IHFACs during noontime June solstice generally flow from the winter to the summer hemisphere (i.e., from the $\mathrm{SH}$ to the $\mathrm{NH}$ ). On the other hand, IHFACs around the SAA flow from the NH to the $\mathrm{SH}$, possibly due to the weak background magnetic field and locally enhanced ionospheric conductivities, which result in a locally persistent summer-like condition in the SH. As equinoctial IHFAC patterns largely follow those of June solstice, we can also expect that equinoctial noontime IHFACs have a C-shape near the SAA. Note that similar, albeit less conspicuous, signatures can be seen for December noon IHFACs (Fig. 8f). However, the above-mentioned theory ('locally summer-like Sq') cannot explain why such C-shapes are hardly identifiable at other MLTs. Near dawn and dusk, the $\mathrm{NH}$ and SH E-regions may experience significantly different insolation depending on seasons and longitudes. This 


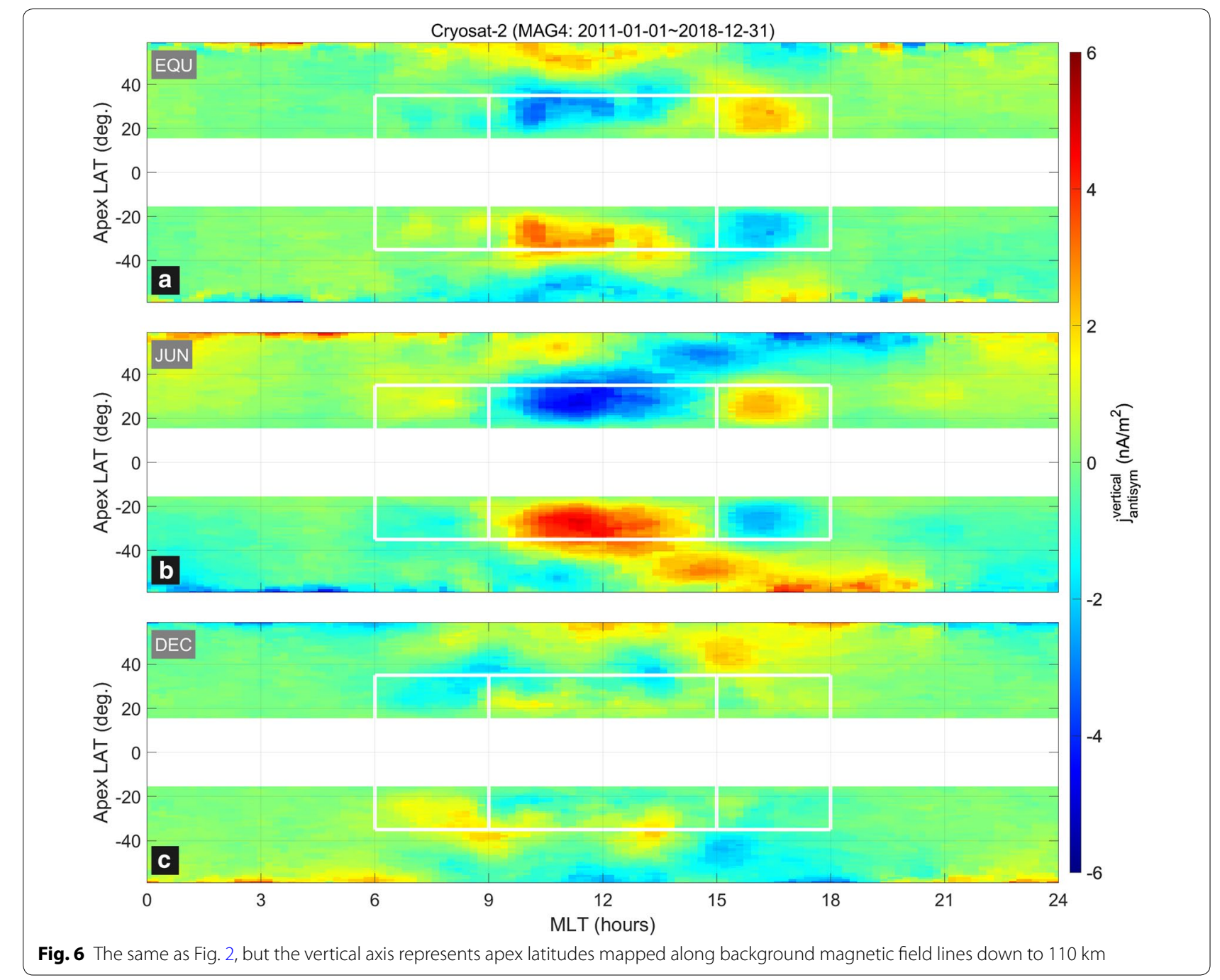

can add complexity to the MLON-MLAT distribution of IHFACs at dawn and dusk. We also speculate that IHFAC distributions can be controlled by an involved interplay between the SAA-induced high conductance and atmospheric tidal effects in the wind, but a dedicated future study is necessary to verify it.

During December solstice, noontime low-latitude IHFACs in Park et al. (2020, Figure 1f) exhibit wavenumber-1 structure, with the polarity changing above the Atlantic and Western Pacific Oceans. Figure $8 \mathrm{f}$ also reproduces this feature, as highlighted by horizontal bidirectional arrows. December dusk-side IHFACs in Fig. 8i have strongest southward currents in the midlatitude Pacific region, which also agrees with Swarm observations (Park et al. 2020, Figure 1i). The consistency between CryoSat-2 (Figs. 2 and 8) and Swarm (Park et al. 2020) confirms the ability of platform magnetometers, after proper post-processing, to investigate low-/mid-latitude ionospheric currents.
Figure 9 is the same as Fig. 8, but for GRACE-FO1. The locations of the horizontal/vertical arrows and C-shaped curves for annotation are the same as in Fig. 8 for the purpose of a direct comparison. Although the data are noisier than in Fig. 8 and containing data gaps (white area), we can still identify the salient features we highlighted in Fig. 8: see the regions inside the red rectangle (near-noon MLT). Wavenumber-4 or -5 structures in the zonal direction can be seen in the noontime low-latitude currents during combined equinoxes and June solstice (panels $\mathrm{d}$ and e) as well as $\mathrm{C}$-shaped structures passing South America and the Atlantic Ocean. On the other hand, the wavenumber-1 structure becomes manifest for noontime December solstice at low latitudes (panel f). All these features agree with those in Fig. 8 and previous reports such as Lühr et al. (2019) and Park et al. (2020). 


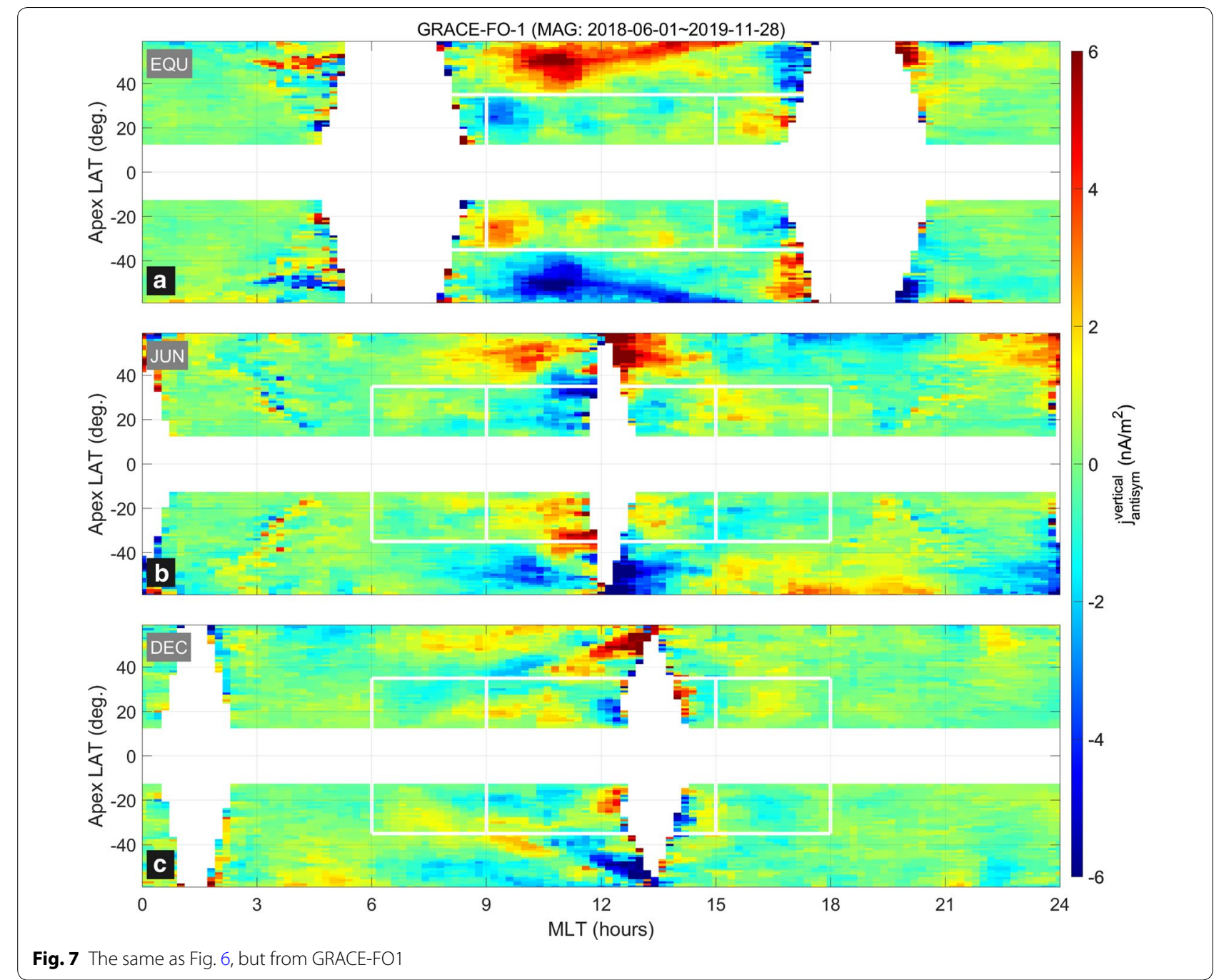

\section{F-region dynamo currents}

The platform magnetometer data could only partially identify the F-region dynamo currents, at least in its traditional sense as reported by previous studies (e.g., Lühr and Maus 2006). In Figs. 4, 5 we can see downward equatorial currents at 12-15 MLT during combined equinoxes and December solstice, as reported in previous studies. However, in other MLT sectors we fail to extract conventionally known signatures of F-region dynamo currents, such as downward currents before noon and clear upward currents near dusk. According to previous studies, the F-region dynamo currents are generally weaker than IHFACs (e.g., Lühr et al. 2015, Figure 4), which can be one reason why the signatures cannot pop out clearly in Figs. 4, 5. Also, the dynamo currents depend significantly on solar activity and altitude: they decrease with increasing altitudes in the F-region (Maute and Richmond 2016, Figure 9) and with decreasing solar activity (Maute and Richmond
2016, Figure 7). Considering higher altitudes of CryoSat-2 $(717 \mathrm{~km})$ and GRACE-FO $(490 \mathrm{~km})$ than those of CHAMP $(<450 \mathrm{~km})$ and Swarm-A/C $(<470 \mathrm{~km})$, it would be natural for the former satellites to encounter weaker currents (possibly below the detection limit of platform magnetometers) of the F-region dynamo than the latter. Also, both CryoSat-2 and GRACE-FO operate within Solar Cycle 24, which is known to be weaker than previous cycles: the two satellites cannot record as strong signatures of the F-region dynamo currents as CHAMP did during the last solar cycle (e.g., Lühr and Maus 2006). Especially, GRACE-FO has been operating right around the current solar minimum. We expect that further data accumulation in the future may reveal the dynamo currents more clearly because the next solar maximum is coming in a few years, and satellite altitudes will be reduced by continuous atmospheric drag. 


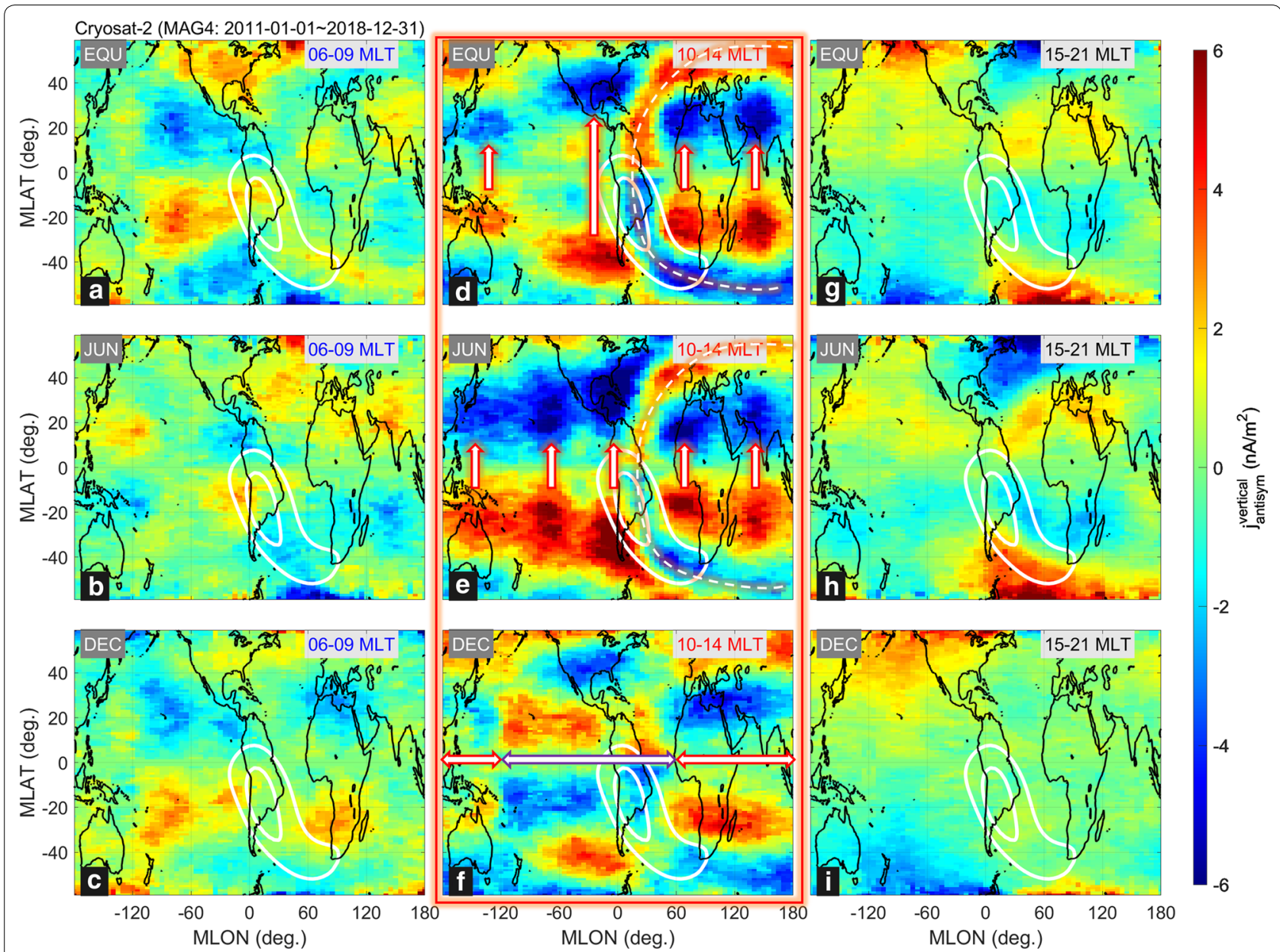

Fig. 8 Geographic distributions of IHFACs estimated from CryoSat-2 data. Each row from the top corresponds to a season: combined equinoxes, June solstice, and December solstice. Three columns from left to right are dawn (06-09 MLT), noon (10-14 MLT), and dusk (15-21 MLT), respectively

\section{Relationship with currents driven by gravity and pressure gradients}

The vertical currents analyzed in this study are deemed (1) IHFACs at off-equatorial latitudes and (2) F-region dynamo currents near the equator. While the low-/midlatitude F-region ionosphere also hosts currents driven by gravity and plasma pressure gradient (e.g., Alken et al. 2016; Maute and Richmond 2017), we do not expect that they have strong effects on our analyses. First, the gravity and pressure gradient currents are mainly in the zonal direction while we focus on vertical currents. Second, these two zonal currents tend to cancel above the F-region peak altitude (e.g., Maute and Richmond 2017, Abstract): that is, where GRACE-FO and CryoSat-2 are located. Third, the periods examined here are mainly during low solar flux, when the ionosphere is in general more tenuous and gravity and pressure gradient currents are weaker than during high solar flux. Fourth, vertical field-aligned currents feeding the two zonal currents are, according to Maute and Richmond (2017 Figure 1), hemispherically symmetric at off-equatorial latitudes and nearly zero at the equator. These current directions are different from those of IHFACs (hemispherically antisymmetric off the equator) and F-region dynamo currents (nonzero at the equator) addressed in this study.

\section{Estimating noise levels of platform magnetometer data}

It would give useful technical information to check the overall fluctuation levels of the vertical current density from platform magnetometer data. Figure 10 has the same structure as Fig. 2, but the color represents absolute values of the 'adjacent difference' (or first-order time derivative) of unfiltered vertical current density. We use 'unfiltered' data to highlight fluctuation levels in the raw data. Also, instead of the combined data out of all the three FGMs onboard CryoSat-2, we use the single FGM1 in this section, which is representative of all the three magnetometers (Olsen et al. 2020). We first calculate the 


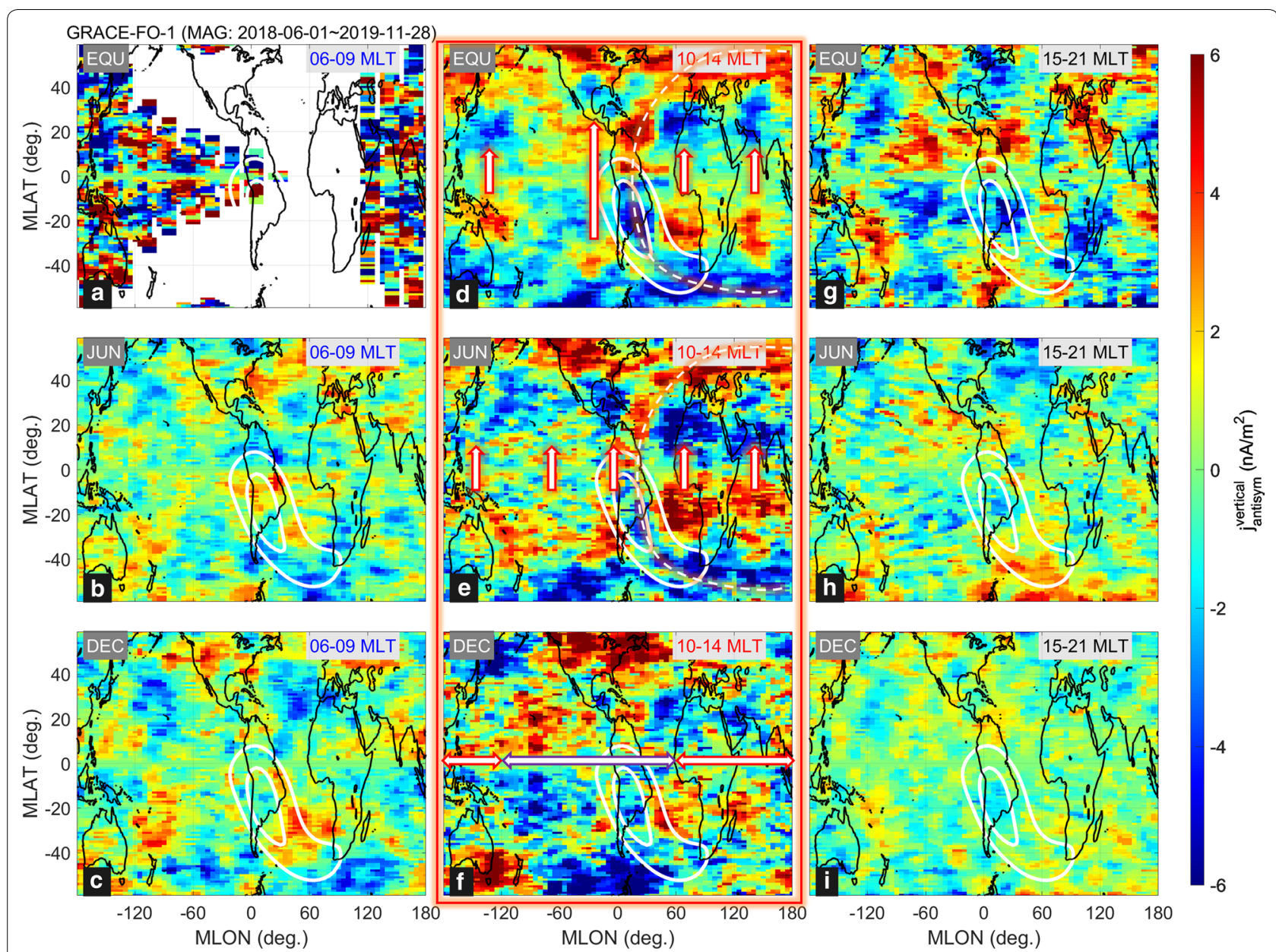

Fig. 9 The same as Fig. 8, but for GRACE-FO1. The locations of the horizontal/vertical arrows and C-shaped curves for annotation are the same as in Fig. 8 for the purpose of a direct comparison

adjacent difference in the time series of vertical current density: $j(t+\mathrm{d} t)-j(t)$, where $j$ is unfiltered vertical current density, $t$ is time, and $d t$ is temporal resolution of the data (4 s for CryoSat-2). Then, its absolute magnitude $(|j(t+\mathrm{d} t)-j(t)|)$ is bin-averaged as a function of MLAT, MLT, and season. The results can give an idea as to how intense the data fluctuations (presumably due to noise of platform magnetometers) are. In Fig. 10, the overall fluctuation levels of CryoSat-2 data are confined to a narrow range between $150 \mathrm{nA} / \mathrm{m}^{2}$ and $180 \mathrm{nA} / \mathrm{m}^{2}$. The fluctuation levels exhibit little dependence on the season, are slightly stronger at $|\mathrm{MLAT}|<35^{\circ}$ than at $|\mathrm{MLAT}|>35^{\circ}$, and have shallow minima near 00 and 12 MLT. These features are different from distributions of geophysical current fluctuations, as reported by earlier studies. According to Aoyama et al. (2017, Figures 1-2) and Yin et al. (2019, Figure 9-10), both of which were based on science-grade magnetometer data onboard Swarm, geophysical magnetic fluctuations (and concomitant current fluctuations) significantly depend on season and MLT. Hence, it is reasonable to conclude that the fluctuations in Fig. 10 mostly originate from instrumental noise and artificial disturbances. The adjacent difference (150-180 $\mathrm{nA} / \mathrm{m}^{2}$ ) much larger than average IHFAC magnitudes (a few $n A / m^{2}$ ) suggests that long-term accumulation of the CryoSat-2 magnetic data (e.g., $>8$ years as in this study) is necessary for getting well-organized IHFAC distributions as shown in Fig. 2. A large amount of data can reduce the standard error of the mean, which decreases with the square root of the bin population.

At the moment, we do not have a good explanation for the low fluctuation levels at mid-latitudes $\left(\mid\right.$ MLAT $\left.\mid>35^{\circ}\right)$ and near the noon-midnight meridian. We speculate that oblique incidence of sunlight on the left or right side of the satellite may disturb the measurement, but further analyses in the future are warranted to verify this conjecture. 

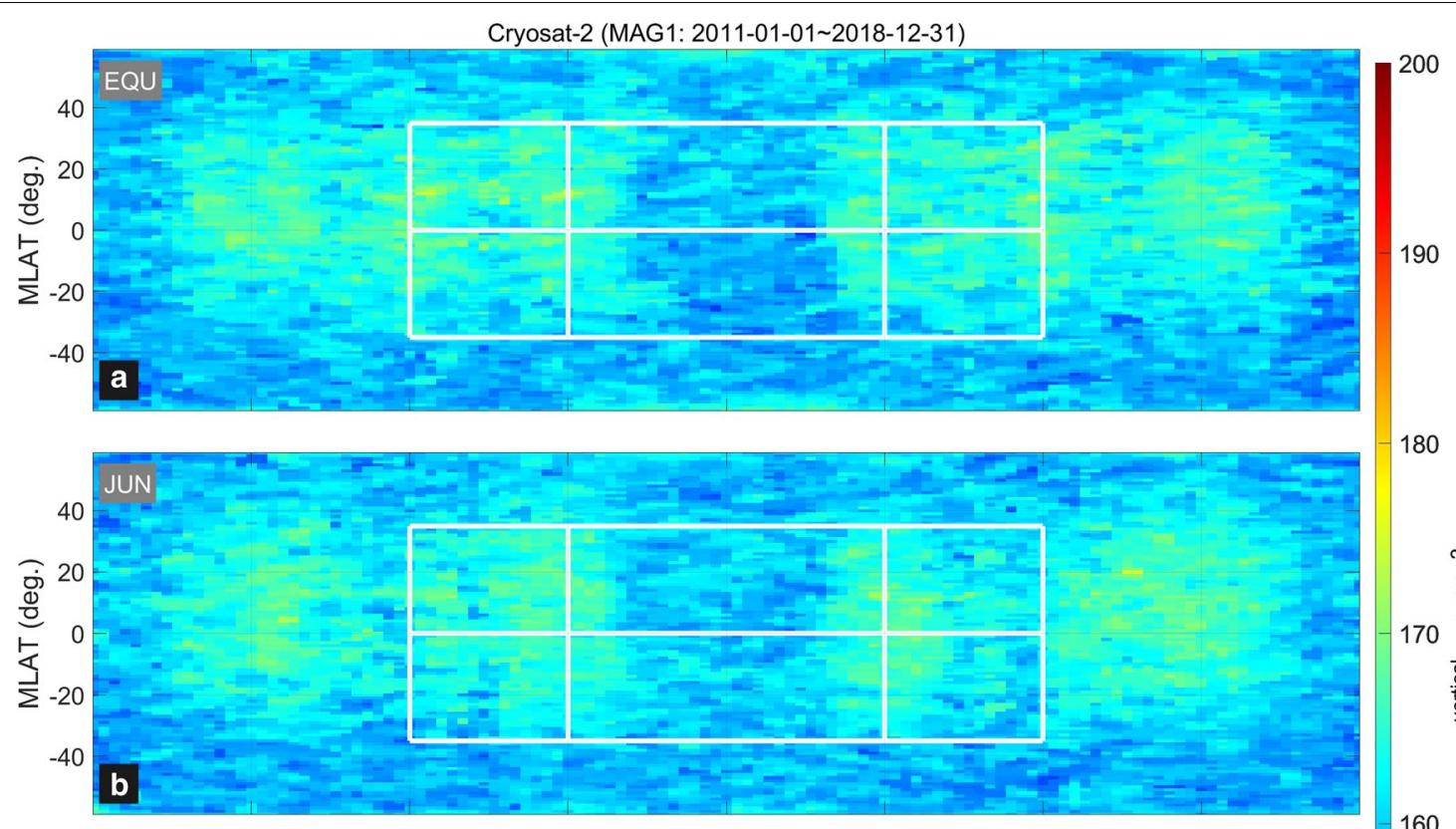

180

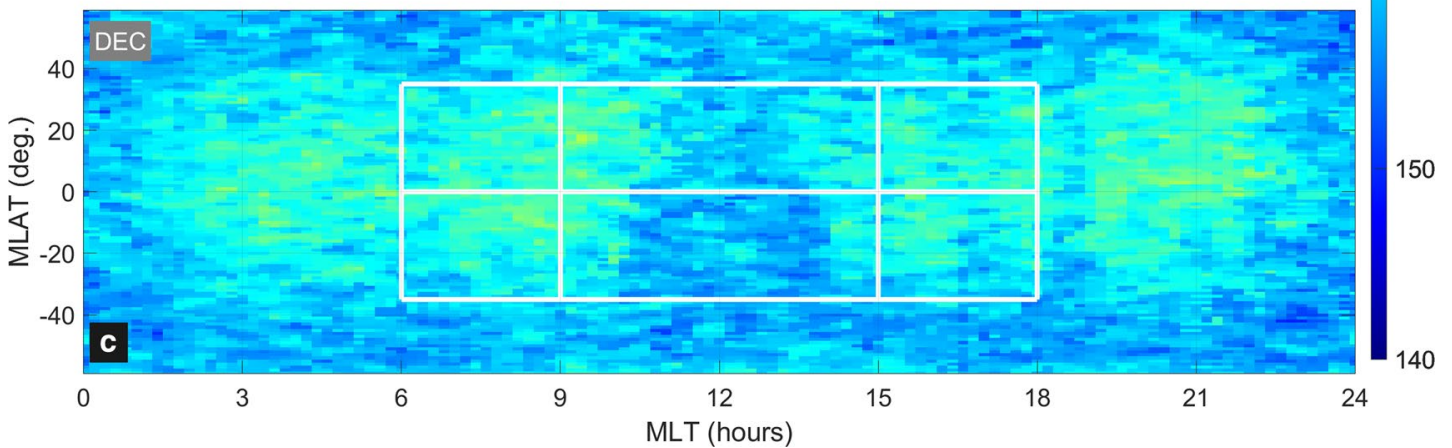

Fig. 10 The same as Fig. 2, but presenting fluctuation levels of vertical current density, which are calculated by absolute magnitude of the adjacent difference of the current density time series

Figure 11 is the same as Fig. 10, but for GRACEFO1. The fluctuation levels are generally stronger than those of CryoSat-2. The stronger fluctuations cannot be attributed solely to the difference in sampling rates ( $4 \mathrm{~s}$ for Cryosat- 2 and $1 \mathrm{~s}$ for GRACE-FO) because both are spot reading values (that is, neither has been timeaveraged to get a smoother signal). The distribution of fluctuation levels in the MLAT-MLT space is complicated and does not conform to previous studies such as Nakanishi et al. (2014, Figure 5) and Aoyama et al. (2017). For example, Aoyama et al. (2017, Figures 2 and 4) report a clear local minimum of fluctuation intensity near the equator and no preference for the summer hemisphere during December solstice. Neither of the features can be seen in our Fig. 11, which suggests that Fig. 11 is also significantly affected by instrument noise and artificial disturbances from the satellite body.
Figure 12 compares fluctuation levels of vertical current density between (a) Swarm, (b) CryoSat-2 (FGM 1 data), and (c) GRACE-FO for an example day on 01 June 2018. For CryoSat-2 and GRACE-FO, black and red dots represent unfiltered and filtered data (with 20-s low-pass filters; see "Satellites, Instruments, and Data Processing Methods" section), respectively. As for Swarm, we just present unfiltered data. Figure 12 shows that the unfiltered platform magnetometer data (black dots: CryoSat-2 and GRACE-FO) exhibit stronger scatter than the science-grade magnetometer data onboard Swarm. However, even Swarm data exhibit significant scatter, which we assume geophysical, in comparison to the averaged IHFAC strength of several $\mathrm{nA} / \mathrm{m}^{2}$. Platform magnetometer data after filtering (red dots) have significantly reduced fluctuation levels, which become nearly comparable to that of Swarm data. Though the fluctuation levels are still larger than several tens of $n A / m^{2}$ in 


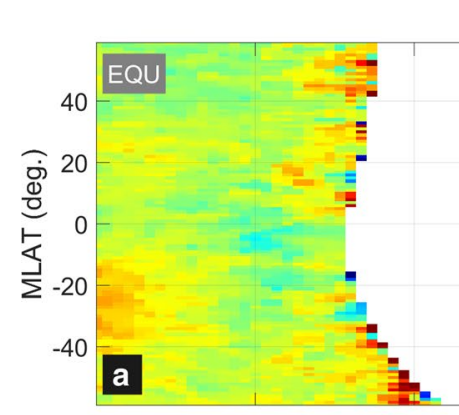

\section{GRACE-FO-1 (MAG: 2018-06-01 2019-11-28)}
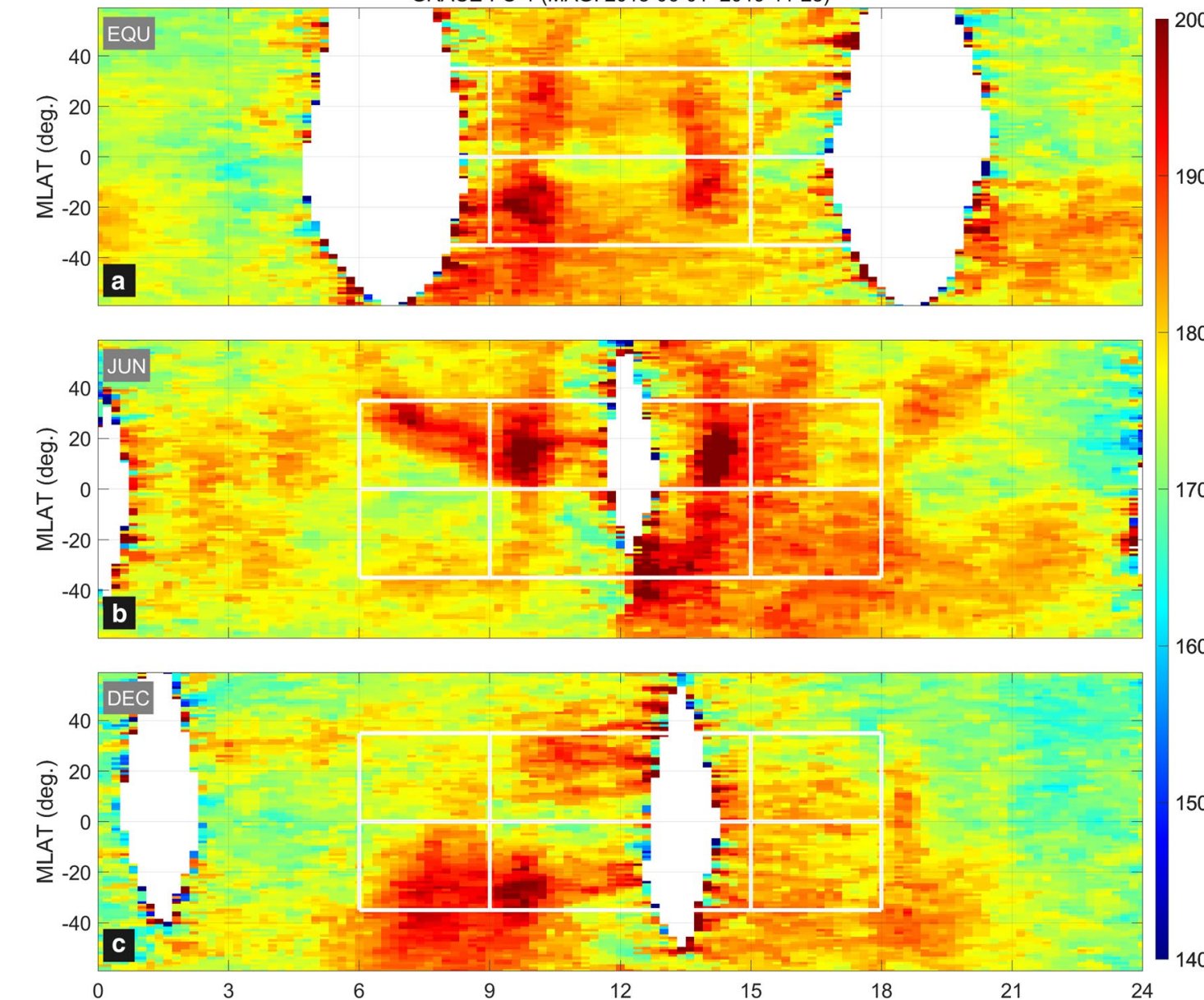

12

MLT (hours)

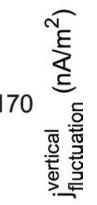

Fig. 11 The same as Fig. 10, but for GRACE-FO1

both the Swarm and filtered platform magnetometer data, long-term accumulation of those data can reproduce the climatology of IHFACs (of the order of one nA/ $\mathrm{m}^{2}$ ), as we have demonstrated throughout this paper. We also checked the standard error of the mean for Figs. 2, 3 , and found that the errors are generally smaller than the magnitude of IHFACs (figures not shown). Note that such low-amplitude currents in platform magnetic field data may depend on the chosen stability of calibration parameters. However, it is an encouraging result that well-known geophysical signals such as IHFACs clearly emerge after data stacking.

\section{Summary and conclusion}

In this study, we have demonstrated that platform magnetometer data can be used for diagnosing low-/midlatitude current systems. CryoSat-2 and GRACE-FO data, after careful post-processing against an empirical magnetic field model, can reproduce well-known climatology of IHFACs as reported earlier by sciencegrade magnetometers onboard LEO satellites. As a new finding, the results show that $\mathrm{C}$-shaped structures in noontime IHFAC distributions conform to the shape of the South Atlantic Anomaly.

Though the data sets only partially identify the F-region dynamo currents, it is not entirely due to the inherent limitations of platform magnetometers. Rather, it may result from low solar activity in the current solar cycle (especially in recent solar-minimum years) and high satellite altitudes, all of which may weaken the dynamo currents. We expect that the F-region dynamo currents may be extracted better in the future when the solar activity rises during Solar Cycle 25, and satellite altitude decreases due to continuous atmospheric drag. As a new scientific achievement, this study evidences noontime F-region dynamo currents at the highest altitudes $(717 \mathrm{~km})$ ever reported. 

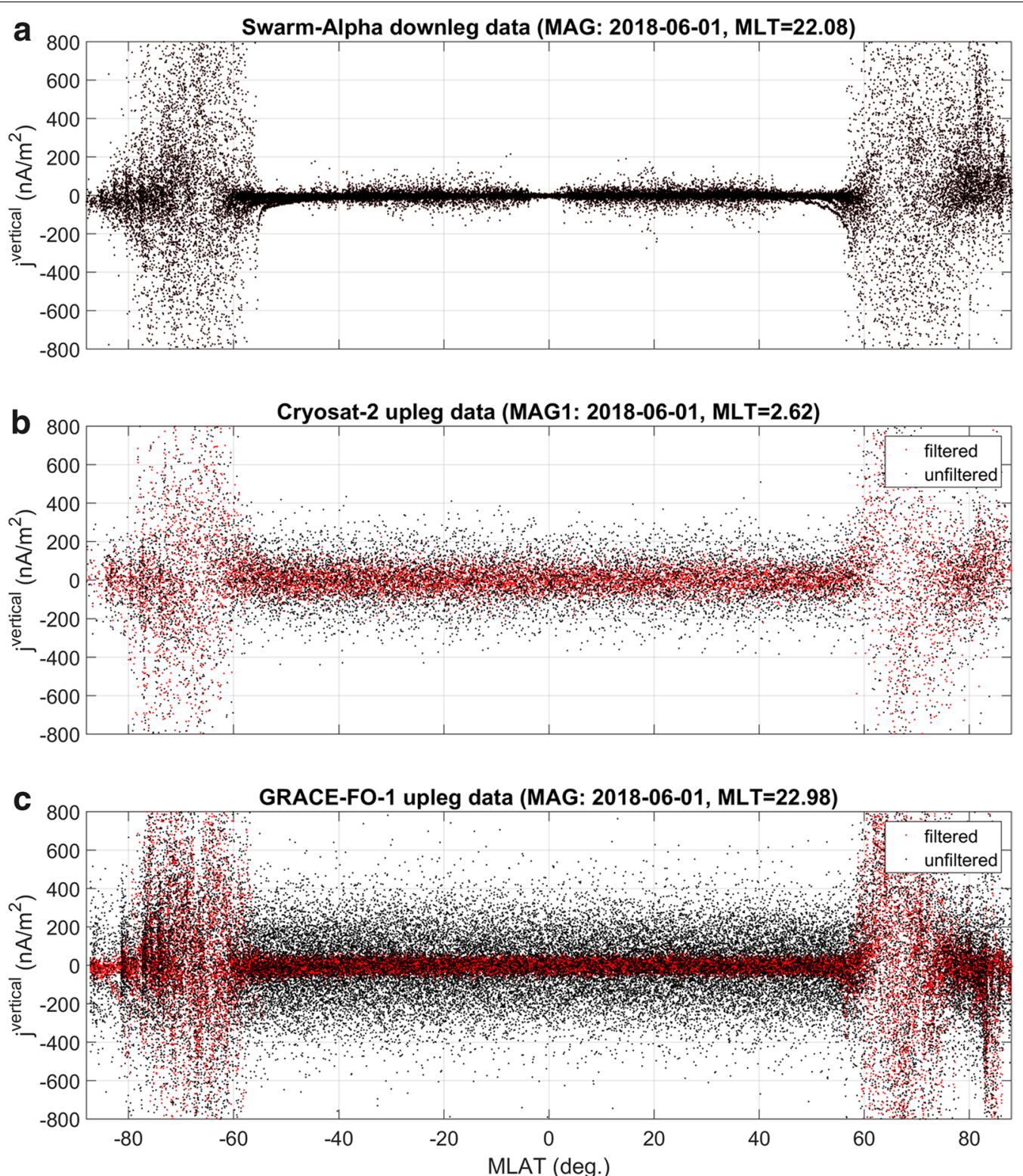

Fig. 12 Scatterplots of unfiltered (black) and filtered (red) vertical current density of a Swarm, b CryoSat-2, and c GRACE-FO for an example day of 01 June 2018

We have also investigated fluctuation intensity in vertical current density as a function of MLAT, MLT, and season. As the fluctuations exhibit patterns utterly different from previous reports based on science-grade magnetometers, we deem those fluctuations largely resulting from artificial magnetic noise.

Besides, platform magnetometers onboard other satellites, such as the Gravity field and Ocean Circulation Explorer (GOCE) and decommissioned GRACE, may provide more information on ionospheric currents under various observation conditions once they are properly calibrated.

\section{Abbreviations}

AMPERE: Active Magnetosphere and Planetary Electrodynamics Response Experiment; CHAMP: Challenging Minisatellite Payload; EEJ: Equatorial ElectroJet; ESA: European Space Agency; FAC: Field-aligned current; FGM: Flux-gate magnetometers; GFZ: GeoForschungsZentrum; GOCE: Gravity field and Ocean Circulation Explorer; GRACE: Gravity Recovery and Climate Experiment; GRACE-FO: Gravity Recovery and Climate Experiment Follow-On; IHFAC: Inter-hemispheric field-aligned current; LEO: Low-earth orbit; LT: Local time; 
MHD: Magneto-HydroDynamic; MLAT: Magnetic latitude; MLON: Magnetic longitude; MLT: Magnetic local time; NH: Northern Hemisphere; SAC-C: Satélite de Aplicaciones Científicas-C; SH: Southern Hemisphere.

\section{Acknowledgements}

The authors are grateful to Hermann Lühr for constructive comments and to Martin Rother for providing helpful ideas for GRACE-FO magnetic data calibration.

\section{Authors' contributions}

JP made figures and wrote the first draft. NO and IM did the full calibration for CryoSat-2 and GRACE-FO magnetic field data, respectively. JR calculated the FAC density out of both CryoSat-2 and GRACE-FO magnetic field data. YY and CS interpreted the data analysis results and gave suggestions for improvement. All authors read and approved the final manuscript.

\section{Funding}

JP was supported by the Air Force Office of Scientific Research (AFOSR) grant FA2386-18-1-0107.

\section{Availability of data and materials}

The CryoSat-2 magnetic data product is available at the ESA official web site (https://swarm-diss.eo.esa.int/\#swarm\%2F\%23CryoSat-2). The GRACE-FO magnetic data are open to the public at the GFZ's Information System and Data Center (ISDC), ftp://isdcftp.gfz-potsdam.de/grace-fo/MAGNETIC_FIELD. $\mathrm{K}_{\mathrm{p}}$ indices are derived and disseminated by GFZ, and both $\mathrm{K}_{\mathrm{p}}$ and $\mathrm{F}_{10.7}$ indices used in this study were downloaded from the NASA OMNIWeb (https:// omniweb.gsfc.nasa.gov/).

\section{Ethics approval and consent to participate}

Not applicable.

\section{Consent for publication}

Not applicable.

\section{Competing interests}

The authors declare to have no competing interests.

\section{Author details}

${ }^{1}$ Space Science Division, Korea Astronomy and Space Science Institute, Daejeon, South Korea. ${ }^{2}$ Department of Astronomy and Space Science, Korea University of Science and Technology, Daejeon, South Korea. ${ }^{3}$ GFZ-German Research Centre for Geosciences, Sect. 2.3, Geomagnetism, Potsdam, Germany. ${ }^{4}$ Faculty of Science, University of Potsdam, Potsdam, Germany. ${ }^{5}$ DTU Space, National Space Institute, Technical University of Denmark, Kongens Lyngby, Denmark.

Received: 8 July 2020 Accepted: 15 September 2020 Published online: 27 October 2020

\section{References}

Alken P, Maus S (2007) Spatio-temporal characterization of the equatorial electrojet from CHAMP, Orsted, and SAC-C satellite magnetic measurements. J Geophys Res. https://doi.org/10.1029/2007JA012524

Alken P, Maus S, Chulliat A, Vigneron P, Sirol O, Hulot G (2015) Swarm equatorial electric field chain: first results. Geophys Res Lett 42:673-680. https://doi. org/10.1002/2014GL062658

Alken P, Maute A, Richmond AD (2016) The F-region gravity and pressure gradient current systems: a review. Space Sci Rev. https://doi.org/10.1007/ s11214-016-0266-z,206,1-4,(451-469)

Anderson BJ, Takahashi K, Toth BA (2000) Sensing global Birkeland currents with iridium ${ }^{\circledR}$ engineering magnetometer data. Geophys Res Lett. https ://doi.org/10.1029/2000GL000094

Anderson BJ, Takahashi K, Kamei T, Waters CL, Toth BA (2002) Birkeland current system key parameters derived from Iridium observations: method and initial validation results. J Geophys Res. https://doi.org/10.1029/2001J A000080

Anderson BJ, Korth H, Waters CL, Green DL, Merkin VG, Barnes RJ, Dyrud LP (2014) Development of large-scale Birkeland currents determined from the active magnetosphere and planetary electrodynamics response experiment. Geophys Res Lett. https://doi.org/10.1002/2014GL059941 Aoyama T, lyemori T, Nakanishi K (2017) Magnetic ripples observed by Swarm satellites and their enhancement during typhoon activity. Earth Planets Space 69:89-109. https://doi.org/10.1186/s40623-017-0679-2

Blagau A, Vogt J (2019) Multipoint field-aligned current estimates with Swarm. J Geophys Res Space Phys 124:6869-6895. https://doi. org/10.1029/2018JA026439

Colomb FR, Varotto CF (2003) SAC-C and the AM constellation: three years of achievements. pp 119-124. https://doi.org/10.1109/ RAST.2003.1303893.

Dunlop MW, Haaland S, Dong XC, Middleton HR, Escoubet CP, Yang YY, Zhang QH, Shi JK, Russell CT (2018) Multipoint analysis of electric currents in geospace using the curlometer technique. Electr Curr Geospace Beyond. 235:67. https://doi.org/10.1002/9781119324522.ch4

Friis-Christensen E, Lühr H, Hulot G (2006) Swarm: a constellation to study the Earth's magnetic field. Earth Planet Sp 58:351-358. https://doi. org/10.1186/BF03351933

Fukushima N (1976) Generalized theorem of no ground magnetic effect of vertical currents connected with Pedersen currents in the uniform conducting ionosphere. Rep lonos Space Res Jpn 30:35-40

Gou X, Li L, Zhang Y, Zhou B, Feng Y, Cheng B, Raita T, Liu J, Zhima Z, Shen $X$ (2020) lonospheric PC1 waves during a storm recovery phase observed by the China Seismo-Electromagnetic Satellite. Ann Geophys 38:775-787. https://doi.org/10.5194/angeo-38-775-2020

Heilig B, Sutcliffe PR (2016) Coherence and phase structure of compressional ULF waves at low-Earth orbit observed by the Swarm satellites. Geophys Res Lett 43:945-951. https://doi.org/10.1002/2015GL067199

Kim H, Hwang J, Park J, Miyashita Y, Shiokawa K, Mann IR, Raita T, Lee J (2018) Large-scale ducting of PC1 pulsations observed by Swarm satellites and multiple ground networks. Geophys Res Lett 45:12703-12712. https://doi.org/10.1029/2018GL080693

Laundal KM, Richmond AD (2017) Magnetic coordinate systems. Space Sci Rev 206:27. https://doi.org/10.1007/s11214-016-0275-y

Laundal KM, Hatch SM, Moretto T (2019) Magnetic effects of plasma pressure gradients in the upper F region. Geophys Res Lett 46:2355-2363. https://doi.org/10.1029/2019GL081980

Lühr H, Maus S (2006) Direct observation of the region dynamo currents and the spatial structure of the EEJ by CHAMP. Geophys Res Lett 33:L24102. https://doi.org/10.1029/2006GL028374

Lühr H, Zhou Y-L (2020) Relation between the asymmetric ring current effect and the anti-sunward auroral currents, as deduced from CHAMP observations. Ann Geophys 38(749-764):2020. https://doi.org/10.5194/ angeo-38-749-2020

Lühr H, Rother M, Maus S, Mai W, Cooke D (2003) The diamagnetic effect of the equatorial Appleton anomaly: its characteristics and impact on geomagnetic field modeling. Geophys Res Lett 30:1906. https://doi. org/10.1029/2003GL017407

Lühr H, Kervalishvili G, Michaelis I, Rauberg J, Ritter P, Park J et al (2015) The interhemispheric and $F$ region dynamo currents revisited with the Swarm constellation. Geophys Res Lett 42:3069-3075. https://doi. org/10.1002/2015GL063662

Lühr H, Kervalishvili GN, Stolle C, Rauberg J, Michaelis I (2019) Average characteristics of low-latitude interhemispheric and F-region dynamo currents deduced from the Swarm satellite constellation. J Geophys Res Space Phys. https://doi.org/10.1002/2019JA027419

Maeda H, Iyemori T, Araki T, Kamei T (1982) New evidence of a meridional current system in the equatorial ionosphere. Geophys Res Lett 9(4):337-340

Maus S, Lühr H (2006) A gravity-driven electric current in the Earth's ionosphere identified in CHAMP satellite magnetic measurements. Geophys Res Lett 33:L02812. https://doi.org/10.1029/2005GL024436

Maute A, Richmond AD (2016) F-region dynamo simulations at low and mid-latitude. Space Sci Rev. https://doi.org/10.1007/s1121 4-016-0262-3,206,1-4,(471-493)

Maute A, Richmond AD (2017) Examining the magnetic signal due to gravity and plasma pressure gradient current with the TIE-GCM. J Geophys Res Space Phys 122:12486-12504. https://doi.org/10.1002/2017JA024841

McGranaghan RM, Mannucci AJ, Forsyth C (2017) A comprehensive analysis of multiscale field-aligned currents: characteristics, controlling parameters, 
and relationships. J Geophys Res Space Phys 122:11931-11960. https:// doi.org/10.1002/2017JA024742

Nakanishi K, lyemori T, Taira K, Lühr H (2014) Global and frequent appearance of small spatial scale field-aligned currents possibly driven by the lower atmospheric phenomena as observed by the CHAMP satellite in middle and low latitudes. Earth Planets Space 66:40. https://doi. org/10.1186/1880-5981-66-40

Neubert T, Mandea M, Hulot G, von Frese R, Primdahl F, Jørgensen JL, FriisChristensen E, Stauning P, Olsen N, Risbo T (2001) Ørsted satellite captures high-precision geomagnetic field data. Eos Trans AGU 82(7):81-88. https ://doi.org/10.1029/01EO00043

Olsen N (1997) lonospheric F region currents at middle and low latitudes estimated from Magsat data. J Geophys Res 102(A3):4563-4576

Olsen N, Stolle C (2012) Satellite Geomagnetism. Annu Rev Earth Planet Sci 40:441-465. https://doi.org/10.1146/annurev-earth-042711-105540

Olsen N, Albini G, Bouffard J et al (2020) Magnetic observations from CryoSat-2: calibration and processing of satellite platform magnetometer data. Earth Planets Space 72:48. https://doi.org/10.1186/s40623-02001171-9

Park J, Lühr H, Stolle C, Rother M, Min KW, Michaelis I (2009) The characteristics of field-aligned currents associated with equatorial plasma bubbles as observed by the CHAMP satellite. Ann Geophys 27:2685-2697. https:// doi.org/10.5194/angeo-27-2685-2009

Park J, Lühr H, Min KW (2010) Characteristics of F-region dynamo currents deduced from CHAMP magnetic field measurements. J Geophys Res 115:A10302. https://doi.org/10.1029/2010JA015604

Park J, Lühr H, Min KW (2011) Climatology of the inter-hemispheric fieldaligned current system in the equatorial ionosphere as observed by CHAMP. Annales de Geophysique 29(3):573-582. https://doi.org/10.5194/ angeo-29-573-2011

Park J, Yamazaki Y, Lühr H (2020) Latitude dependence of interhemispheric field-aligned currents (IHFACs) as observed by the Swarm constellation. J Geophys Res Space Phys. https://doi.org/10.1029/2019JA027694

Reigber C, Lühr H, Schwintzer P, Wickert J (2005) Earth observation with CHAMP_results from three years in orbit. Springer, Berlin Heidelberg

Richmond AD (1995) lonospheric electrodynamics using magnetic apex coordinates. J Geomagn Geoelectr 47:191-212

Rishbeth H (1971a) The F-layer dynamo. Planet Space Sci 19:263

Rishbeth H (1971b) Polarization fields produced by winds in the equatorial F-region. Planet Space Sci 19(3):357-369. https://doi.org/10.1016/00320633(71)90098-5
Ritter P, Lühr H, Rauberg J (2013) Determining field-aligned currents with the Swarm constellation mission. Earth Planet Space 65:9. https://doi. org/10.5047/eps.2013.09.006

Rodríguez-Zuluaga J, Stolle C, Park J (2017) On the direction of the Poynting flux associated with equatorial plasma depletions as derived from Swarm Geophys Res Lett 44:5884-5891. https://doi.org/10.1002/2017GL073385

Rodríguez-Zuluaga J, Stolle C, Yamazaki Y, Lühr H, Park J, Scherliess L, Chau JL (2019) On the balance between plasma and magnetic pressure across equatorial plasma depletions. J Geophys Res Space Phys 124:5936-5944

Shinbori A, Koyama Y, Nosé M, Hori T, Otsuka Y (2017) Characteristics of seasonal variation and solar activity dependence of the geomagnetic solar quiet daily variation. J Geophys Res Space Phys 122:10796-10810. https:// doi.org/10.1002/2017JA024342

Smith ARA, Beggan CD, Macmillan S, Whaler KA (2017) Climatology of the auroral electrojets derived from the along-track gradient of magnetic field intensity measured by POGO, Magsat, CHAMP, and Swarm. Space Weather 15:1257-1269. https://doi.org/10.1002/2017SW001675

Stolle C, Lühr H, Rother M, Balasis G (2006) Magnetic signatures of equatorial spread F as observed by the CHAMP satellite. J Geophys Res 111:A02304. https://doi.org/10.1029/2005JA011184

Wu J, Knudsen DJ, Gillies DM, Donovan EF, Burchill JK (2017) Swarm observation of field-aligned currents associated with multiple auroral arc systems. J Geophys Res Space Phys 122:10145-10156. https://doi. org/10.1002/2017JA024439

Yamashita S, Iyemori T (2002) Seasonal and local time dependences of the interhemispheric field-aligned currents deduced from the Orsted satellite and the ground geomagnetic observations. J Geophys Res 107(A11):1372

Yamazaki Y, Maute A (2017) Sq and EEJ_a review on the daily variation of the geomagnetic field caused by ionospheric dynamo currents. Space Sci Rev 206(1-4):299-405. https://doi.org/10.1007/s11214-016-0282-z

Yin F, Lühr H, Park J, Wang L (2019) Comprehensive analysis of the magnetic signatures of small-scale traveling ionospheric disturbances, as observed by Swarm. J Geophys Res Space Phys 124:10794-10815. https://doi. org/10.1029/2019JA027523

\section{Publisher's Note}

Springer Nature remains neutral with regard to jurisdictional claims in published maps and institutional affiliations.

\section{Submit your manuscript to a SpringerOpen ${ }^{\circ}$ journal and benefit from:}

- Convenient online submission

- Rigorous peer review

- Open access: articles freely available online

- High visibility within the field

- Retaining the copyright to your article

Submit your next manuscript at $\boldsymbol{\nabla}$ springeropen.com 